\title{
Transmural Mesh Migration From the Abdominal Wall to the Rectum After Hernia Repair Using a Prolene Mesh: A Case Report
}

\author{
Yujin Lee, Byung-Noe Bae \\ Department of General Surgery, Sanggye Paik Hospital, Inje University College of Medicine, Seoul, Korea
}

Mesh erosion or migration is a rare and late complication after hernia repair. Its incidence is increasing as the utilization of prosthetic mesh gains popularity for abdominal hernia repair. However, mesh migration is exceedingly rare and its clinical presentation is atypical and diverse. Therefore, the management of mesh migration should be individualized to each patient. This research reports the case of a 94-year-old man with transmural migration of Prolene mesh (Ethicon) from the abdominal wall to the rectum 14 years after incisional hernia repair. He presented with only chronic abdominal pain and constipation. Migration of the mesh and a fistula between the right abdominal wall and transverse colon was observed on computed tomography. The mesh was evacuated manually from the anus without any sequelae. These findings made this case atypical, since complete transluminal migration of mesh is exceedingly rare and mesh erosion or migration requires surgical treatment in many cases.

Keywords: Incisional hernia; Herniorrhaphy; Surgical mesh; Complications

\section{INTRODUCTION}

Incisional hernia is one of the most commonly reported complications after abdominal surgery [1]. The application of different types of synthetic mesh for abdominal wall and hernia repair has increased. Mesh repair enables tension-free repair and reduces the overall recurrence rate compared to that of primary repair [2]. Despite its advantages, complications including seroma, mesh infection, fistula formation, erosion, and migration occur infrequently [3]. Mesh migration is very rare and difficult to diagnosis because of its broad spectrum of clinical presentation. We present an interesting case of transmural mesh migration from the abdominal wall to the rectum following abdominal wall repair with review of literature.

Received: Dec 16, 2019 - Revised: Mar 30, 2020 - Accepted: Apr 19, 2020

Correspondence to: Byung-Noe Bae, M.D., Ph.D.

Department of General Surgery, Sanggye Paik Hospital, Inje University

College of Medicine, 1342 Dongil-ro, Nowon-gu, Seoul 01757, Korea

Tel: +82-2-950-1017, Fax: +82-2-950-1429.

E-mail: bnbae@paik.ac.kr

ORCID: https://orcid.org/0000-0002-5542-5626

(C) 2021 The Korean Society of Coloproctology

This is an open-access article distributed under the terms of the Creative Commons Attribution NonCommercial License (https://creativecommons.org/licenses/by-nc/4.0) which permits unrestricted non-

commercial use, distribution, and reproduction in any medium, provided the original work is properly cited.

\section{CASE REPORT}

This study was reviewed by Institutional Review Board (IRB) of Inje University Sanggye Paik Hospital (No. 2019-12-009). IRB waived the need for informed consent on this case report.

A 94-year-old man with a past medical history of hypertension presented to the emergency department complaining of constipation and anal discomfort. He failed to defecate for a week, and then the anal discomfort was aggravated by the initiation of defecation. In 2003, he underwent right hemicolectomy due to intussusception, with a final diagnosis of colon cancer. He underwent a second surgery due to wound evisceration on postoperative day (POD) 6. Both surgeries were performed through a right paramedian incision. The wound was reinforced using polypropylene (Prolene, Ethicon, Cincinnati, OH, USA) mesh, and the fascia was closed over the mesh by interrupted sutures with black silk. There was no record about the exact size of the abdominal wall defect and the mesh applied. The postoperative course of the second surgery was uneventful, and the patient was discharged on POD 16. He completed chemotherapy and a routine follow-up of 3 years without any complaint. The last computed tomography (CT) scan was performed as part of a routine follow-up visit in 2006, and it showed sheet-like foreign material in the retrorectus muscle area of the right midabdominal wall (Fig. 1). The patient 


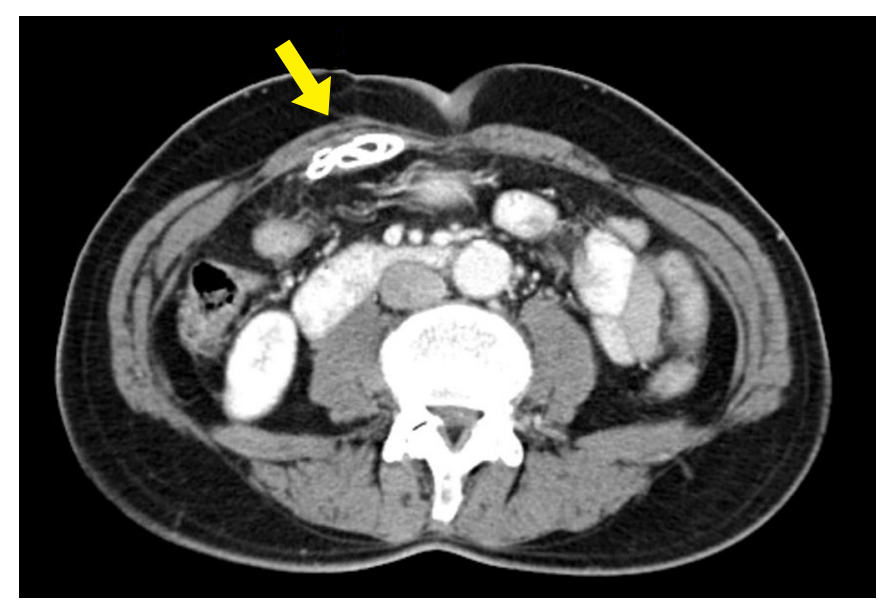

Fig. 1. An image from computed tomography taken in 2006. A sheet-like foreign material (arrow) is observed in the preperitoneal space of the right midabdominal wall.

was asymptomatic until 2013, when he began to experience constipation and discomfort in the vicinity of the previous surgical wound. He was treated conservatively and did not need to return for any further treatment for 2 years.

In April 2015, on the day of the visit, physical examination of the abdomen was unremarkable. However, the rectal exam revealed a foreign body covered with feces in the anal canal. The lab work revealed mild elevation of the white blood cell count $(12,680 / \mu \mathrm{L})$ and C-reactive protein $(0.6 \mathrm{mg} / \mathrm{dL})$. While a kidney, ureter, and bladder (KUB) X-ray taken 2 years earlier showed surgical material in the right abdomen (Fig. 2A), the KUB X-ray showed surgical material in the pelvic cavity (Fig. 2B). Abdominopelvic CT indicated a fistula between the right anterior abdominal wall and transverse colon (Fig. 3A). Foreign material observed on the last CT scan was not visible in the retrorectus area, as was previously observed (Fig. 3B), but instead was visible in the rectum (Fig. 3C), which was consistent with the migration of mesh into the transverse colon and its intraluminal passage to the rectum.

The foreign body was evacuated manually from the anus, and it was confirmed as an intact piece of Prolene mesh. After the procedure, the patient felt better and was instructed to gradually progress from oral intake of sips of water to ingestion of solid food. He did not have peritoneal signs that suggested leakage of bowel contents into the abdominal cavity, and the lab tests showed no signs of inflammation. The patient was discharged after an uneventful week of observation. Four months later, the patient visited the outpatient clinic with complaints of vague abdominal discomfort, but the abdominal physical examination did not reveal any abnormal findings or sign of hernia. A previously noted fistula between the right anterior abdominal wall and transverse colon was not visible on the follow-up CT scan.
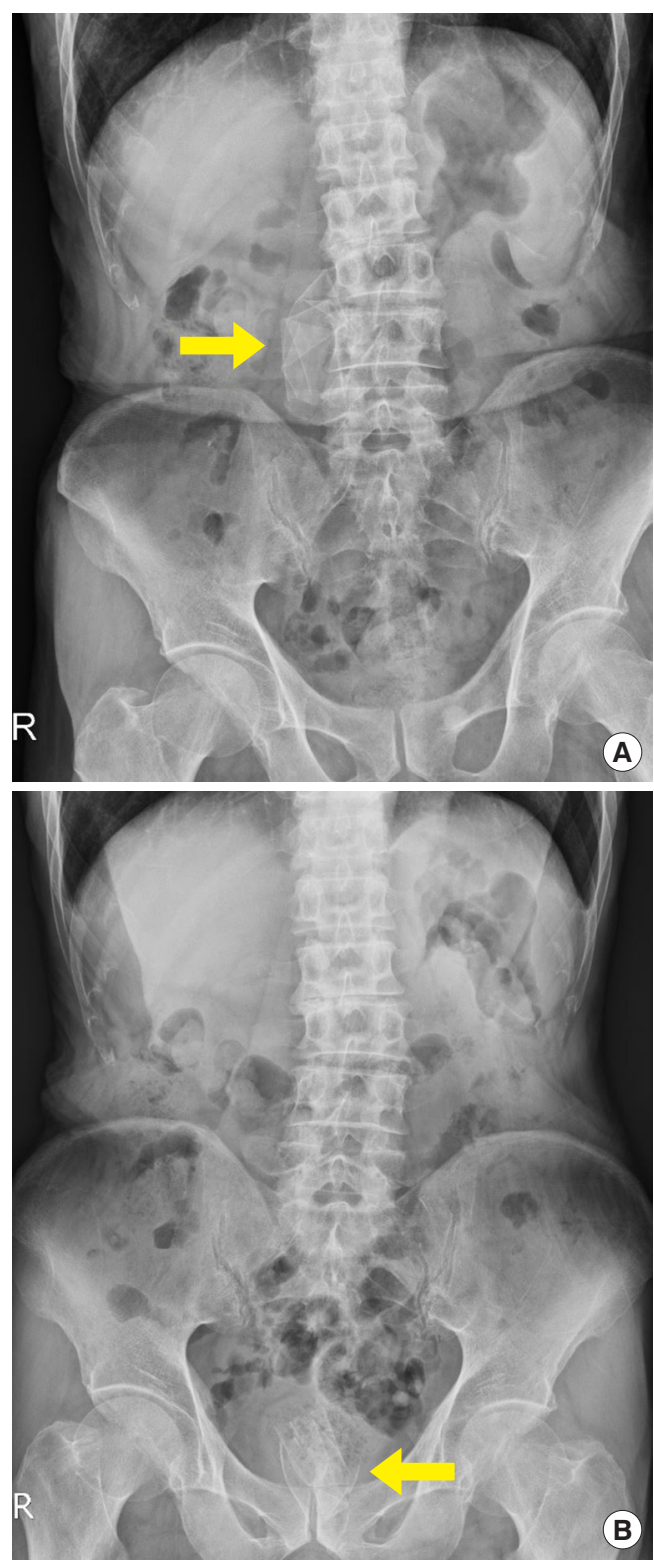

Fig. 2. Images of kidney ureter, and bladder X-ray. (A) The image taken in 2013 shows surgical material (arrow) at the right side of abdomen. (B) The image taken in 2015 shows surgical material (arrow) in the pelvic cavity.

\section{DISCUSSION}

The utilization of synthetic mesh for repairing wounds and hernias has been a common practice due to associated favorable outcomes. Synthetic mesh minimizes the amount of tension that is placed on the abdominal wall and reduces the overall recurrence rate of hernia [4]. The recurrence rate of incisional hernia after mesh repair, an open procedure, or a laparoscopic procedure has been reported to be lower than $10 \%$, whereas the recurrence rate 


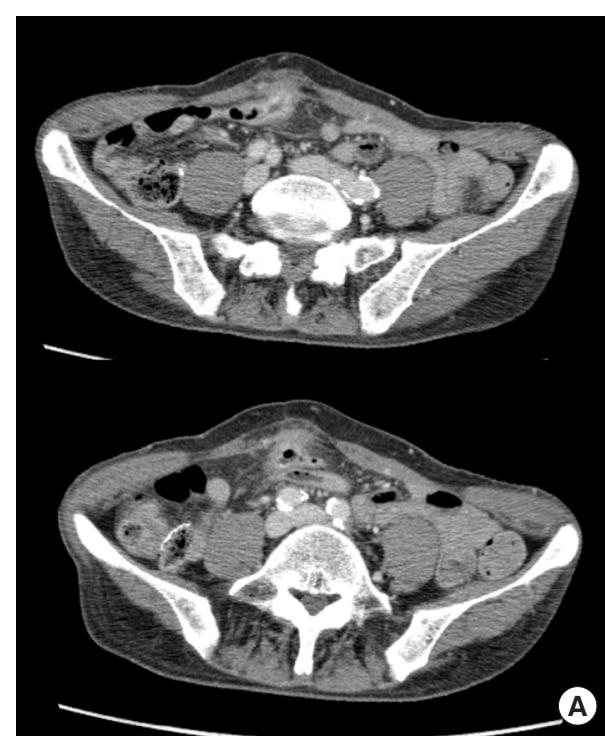

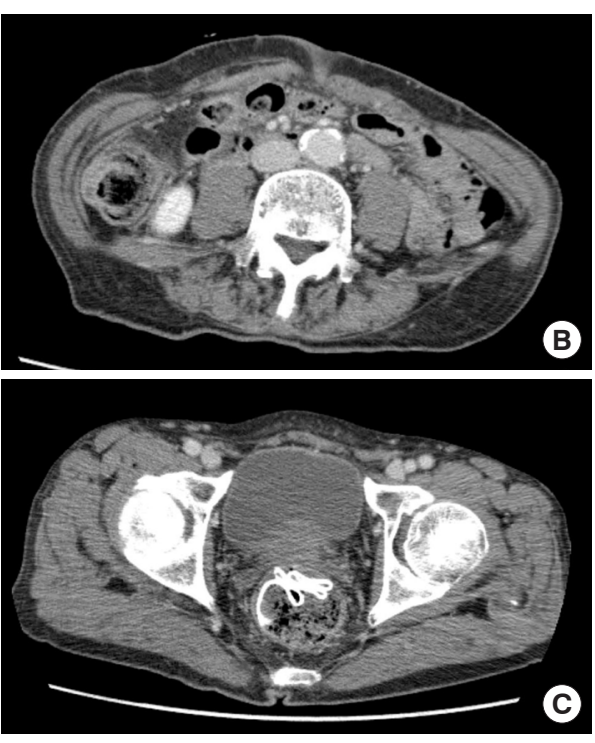

Fig. 3. Images from computed tomography (CT) taken in 2015. (A) A fistula between the right anterior abdominal wall and transverse colon is seen. (B) Foreign material observed in the previous CT scan is not visible in the retro-rectus area. (C) Sheet-like foreign material is seen in rectum. following open suture repair is reportedly as high as 31\% to $49 \%$ [2]. Mesh insertion is important, especially in the case of a large incisional hernia over $4 \mathrm{~cm}$, which is related to a high recurrence rate due to higher tension placed on the defect [5].

Complications associated with the use of mesh are relatively rare, and the exact incidence of mesh migration from the abdominal wall to hollow viscus is not known because of the extreme rarity of its occurrence. Cunningham et al. [6] defined "mesh migration" as invasion of an organ by the entire mesh; "mesh migration" is distinguished from "mesh erosion" in that "mesh erosion" is a partial displacement of the mesh into an organ with a portion remaining outside. According to a report based on an U.S. Food and Drug Administration database review, migration or erosion of mesh accounted for $2 \%$ of 252 major mesh-related complications following hernia repair [7]. However, published reports concerning mesh migration or erosion have increased as mesh procedures become popular for incisional hernia repair [6]. In addition, the incidence of mesh migration or erosion might be higher than reported because of under-reporting and delayed presentation; e.g., > 10 years after surgery $[5,8]$.

The mechanism of mesh migration has been reported previously in the literature [5]. Primary migration consists of movement along adjoining anatomical planes of least resistance following inadequate fixation of the mesh. A secondary mechanism that explains transanatomical migration is the result of erosion triggered by chronic inflammation [5]. Fistula formation, as observed in this case, is a common sequela of erosion.

Symptoms induced by mesh migration or erosion are atypical and related to the organ involved [5]. Various clinical presentations have been reported in relation to mesh erosion into the small bowel or large bowel; e.g., chronic pain [5], accompanied by rectorrhagia [8], chronic anemia [9], enterocutaneous fistula [10], and bowel obstruction [10]. One case reported asymptomatic mesh migration [11]. Constipation and anal discomfort were the main complaints in our case.

According to the diversity of clinical presentation, the management plan should be individualized to each patient considering the involved viscera, extent of invasion, possibility of endoscopic removal, and overall condition of the patient [6]. Invasive surgeries including en-bloc bowel resection and anastomosis are required when severe complications of mesh migration or erosion such as enterocutaneous fistula and intestinal bleeding occur [9, 10], or when the mesh cannot be removed endoscopically.

In this case, the migrated mesh was removed by simple manual extraction through the anus without an invasive procedure such as endoscopy or surgery. Complete intraluminal placement after mesh migration is exceedingly rare [5]. Another case reported spontaneous mesh evacuation through the rectum 2 years after incisional hernia repair by intraperitoneal placement of polypropylene and expanded polytetrafluoroethylene mesh [12]. However, our patient was treated with preperitoneal placement of Prolene mesh and presented with a mesh-related complication 14 years later. Patients in both cases did not present any evidence of enterocutaneous fistula other than chronic abdominal pain and constipation, and the symptom was relieved without surgery. Chronic pain after incisional hernia repair with mesh is common. A retrospective analysis of 109 patients revealed that 31 patients (28\%) had chronic pain; however, they did not present with complications related to mesh erosion or migration such as enterocutaneous fistula and bowel obstruction, which might be due to a relatively short duration of follow-up (a mean follow-up period of 24.6 months) in that study [13]. Typically, mesh erosion or migration usually takes several years to occur.

Unlike our case, mesh erosion or migration can lead to a catastrophic event; thus, efforts to prevent complications are important. Many contributing factors have been studied such as types 


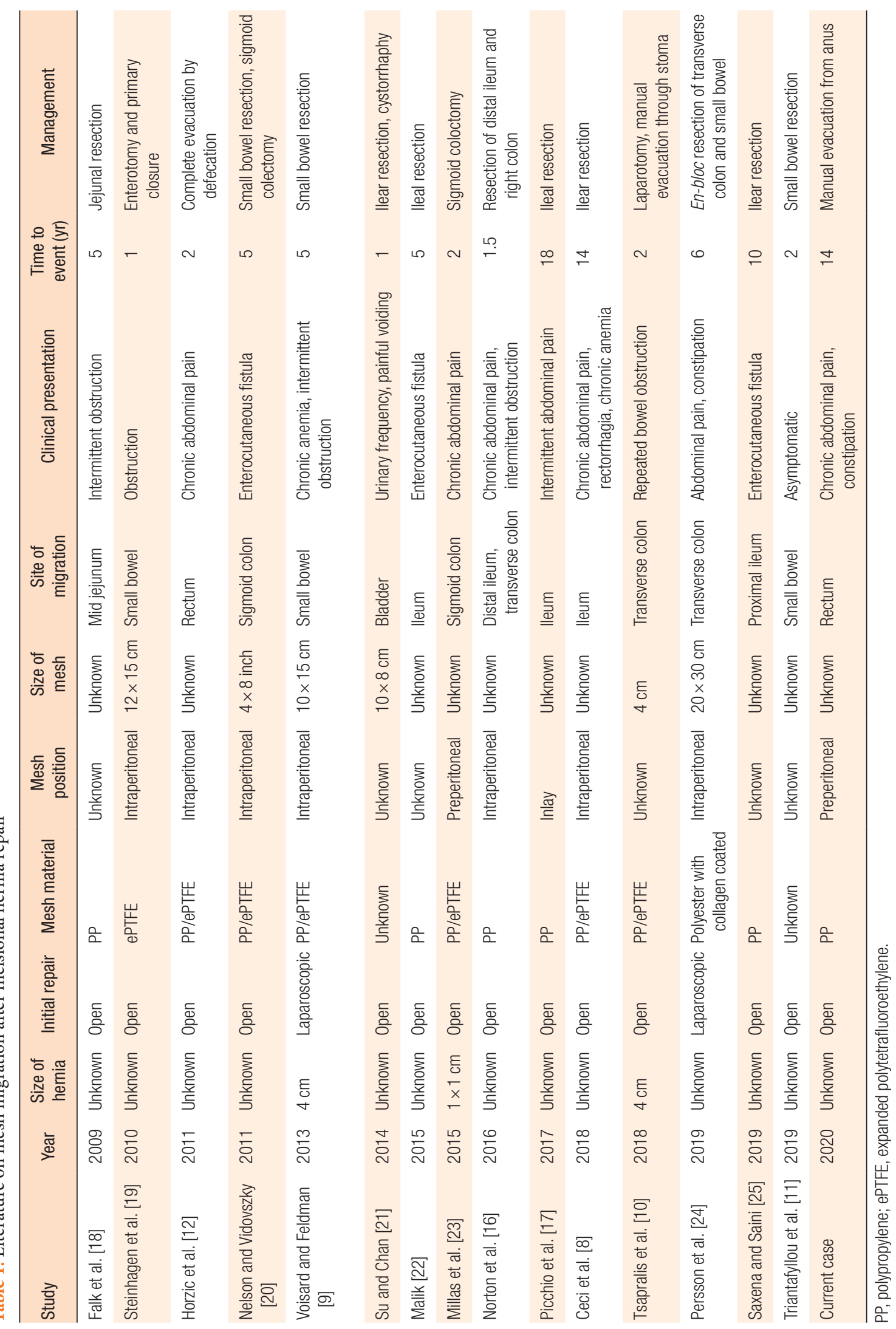


and sizes of mesh, anatomical placement of mesh (intraperitoneal or extraperitoneal), methods of fixation, and underlying conditions of patients [6]. Several articles proposed the importance of avoiding direct contact of abdominal organs with the mesh to prevent mesh migration or erosion [11, 14]. Basoglu et al. [14] reported that enterocutaneous fistula occurred significantly more often in patients lacking peritoneal or omental coverage.

Optimal mesh type to avoid mesh migration has not been established. A review article reported that polypropylene was the most frequently used mesh in migration cases; however, the author mentioned that the popularity of polypropylene mesh was contributory to the result [6]. Polypropylene mesh was generally reported to be invisible or poorly visible with CT scan [15]. However, there were several cases with polypropylene mesh migration which was visible with CT scan $[16,17]$. Table 1 shows the characteristic of 15 publications about mesh migration after incisional hernia repair [8-12, 16-25].

This is an atypical presentation of a case of complete transluminal migration of mesh initially placed in the preperitoneal space without specific symptoms, other than chronic pain; the mesh was simply removed manually through the anus. Clinicians ought to be aware of the possibility of mesh erosion or migration as a late complication of prosthetic mesh and its atypical presentation. Patients should be provided with information about this rare but occasionally serious complication.

\section{CONFLICT OF INTEREST}

No potential conflict of interest relevant to this article was reported.

\section{REFERENCES}

1. Mutwali IM. Incisional hernia: risk factors, incidence, pathogenesis, prevention and complications. Sudan Med Monit 2014;9:81-6.

2. Cassar K, Munro A. Surgical treatment of incisional hernia. Br J Surg 2002;89:534-45.

3. Patil AR, Nandikoor S, Mohanty HS, Godhi S, Bhat R. Mind the gap: imaging spectrum of abdominal ventral hernia repair complications. Insights Imaging 2019;10:40.

4. Burger JW, Luijendijk RW, Hop WC, Halm JA, Verdaasdonk EG, Jeekel J. Long-term follow-up of a randomized controlled trial of suture versus mesh repair of incisional hernia. Ann Surg 2004; 240:578-83.

5. Gandhi D, Marcin S, Xin Z, Asha B, Kaswala D, Zamir B. Chronic abdominal pain secondary to mesh erosion into cecum following incisional hernia repair: a case report and literature review. Ann Gastroenterol 2011;24:321-4.

6. Cunningham HB, Weis JJ, Taveras LR, Huerta S. Mesh migration following abdominal hernia repair: a comprehensive review. Hernia 2019;23:235-43.

7. Robinson TN, Clarke JH, Schoen J, Walsh MD. Major mesh-relat- ed complications following hernia repair: events reported to the Food and Drug Administration. Surg Endosc 2005;19:1556-60.

8. Ceci F, D’Amore L, Annesi E, Bambi L, Grimaldi MR, Gossetti F, et al. Chronic anemia due to transmural e-PTFE anti-adhesive barrier mesh migration in the small bowel after open incisional hernia repair: a case report. Int J Surg Case Rep 2018;53:54-7.

9. Voisard G, Feldman LS. An unusual cause of chronic anemia and abdominal pain caused by transmural mesh migration in the small bowel after laparoscopic incisional hernia repair. Hernia 2013;17:673-7.

10. Tsapralis D, Vasiliades G, Zaxou Z, Delimpaltadaki M, Margetousakis TH, Papadakis $\mathrm{H}$, et al. Bowel obstruction secondary to migration of a Ventralex mesh: report of a rare complication. Hernia 2018;22:711-4.

11. Triantafyllou E, Anastasiadis I, Konstantinidis D, Syllaios A, Gerovasileiou E, Tsiripidis O. Asymptomatic migration of ventral mesh for incisional hernia into the small intestine: a case report. Clin Case Rep 2019;7:1339-41.

12. Horzic M, Vergles D, Cupurdija K, Kopljar M, Zidak M, Lackovic $Z$. Spontaneous mesh evacuation per rectum after incisional ventral hernia repair. Hernia 2011;15:351-2.

13. Gronnier C, Wattier JM, Favre H, Piessen G, Mariette C. Risk factors for chronic pain after open ventral hernia repair by underlay mesh placement. World J Surg 2012;36:1548-54.

14. Basoglu M, Yildirgan MI, Yilmaz I, Balik A, Celebi F, Atamanalp SS, et al. Late complications of incisional hernias following prosthetic mesh repair. Acta Chir Belg 2004;104:425-8.

15. Rakic S, LeBlanc KA. The radiologic appearance of prosthetic materials used in hernia repair and a recommended classification. AJR Am J Roentgenol 2013;201:1180-3.

16. Norton C, Culver A, Mostafa G. Intraluminal mesh migration after ventral hernia repair. J Gastrointest Surg 2016;20:1920-2.

17. Picchio M, Muggianu A, Mancini F, Tintisona O, Spaziani E. Complete mesh migration into the small bowel after incisional hernia repair: a case report and literature review. Acta Chir Belg 2017;117:118-21.

18. Falk GA, Means JR, Pryor AD. A case of ventral hernia mesh migration with splenosis mimicking a gastric mass. BMJ Case Rep 2009;2009:bcr06.2009.2033.

19. Steinhagen E, Khaitov S, Steinhagen RM. Intraluminal migration of mesh following incisional hernia repair. Hernia 2010;14:65962 .

20. Nelson EC, Vidovszky TJ. Composite mesh migration into the sigmoid colon following ventral hernia repair. Hernia 2011;15: 101-3.

21. Su YR, Chan PH. Mesh migration into urinary bladder after open ventral herniorrhaphy with mesh: a case report. Int Surg 2014;99: 410-3.

22. Malik AM. Intra-intestinal mesh migration presenting with faecal fistula after incisional hernia repair. J Pak Med Assoc 2015;65: 322-3.

23. Millas SG, Mesar T, Patel RJ. Chronic abdominal pain after ven- 
tral hernia due to mesh migration and erosion into the sigmoid colon from a distant site: a case report and review of literature. Hernia 2015;19:849-52.

24. Persson P, Scrimgeour DS, Parnaby C. Mesh migration-should it be a mandatory consentable complication? J Case Rep Images
Surg 2019;5:100057Z12PP2019.

25. Saxena K, Saini R. Enterocutaneous fistula secondary to mesh erosion of bowel: a late complication of polypropylene mesh use in ventral hernia repair. Int Surg J 2019;6:4163-6. 